\title{
Evapotranspiration of grapevine trained to a gable trellis system under netting and black plastic mulching
}

\author{
R. Moratiel • A. Martínez-Cob
}

\begin{abstract}
The evapotranspiration $\left(E T_{c}\right)$ of a table grape vineyard (Vitis vinifera, cv. Red Globe) trained to a gable trellis under netting and black plastic mulching was determined under semiarid conditions in the central Ebro River Valley during 2007 and 2008. The netting was made of high-density polyethylene (pores of $12 \mathrm{~mm}^{2}$ ) and was placed just above the ground canopy about $2.2 \mathrm{~m}$ above soil surface. Black plastic mulching was used to minimize soil evaporation. The surface renewal method was used to obtain values of sensible heat flux $(H)$ from high-frequency temperature readings. Later, latent heat flux $(L E)$ values were obtained by solving the energy balance equation. For the May-October period, seasonal $E T_{\text {c }}$ was about $843 \mathrm{~mm}$ in 2007 and $787 \mathrm{~mm}$ in 2008. The experimental weekly crop coefficients $\left(K_{\text {cexp }}\right.$ ) fluctuated between 0.64 and 1.2. These values represent crop coefficients adjusted to take into account the reduction in $E T_{c}$ caused by the netting and the black plastic mulching. Average $K_{\text {cexp }}$ values during mid- and end-season stages were 0.79 and 0.98 , respectively. End-season $K_{\text {cexp }}$ was higher due to combination of factors related to the precipitation and low $E T_{\mathrm{o}}$ conditions
\end{abstract}

that are typical in this region during fall. Estimated crop coefficients using the Allen et al. (1998) approach adjusting for the effects of the netting and black plastic mulching $\left(K_{\mathrm{cFAO}}\right)$ showed a good agreement with the experimental $K_{\text {cexp }}$ values.

\section{Introduction}

Table grapes (Vitis vinifera L.) are a profitable crop in the semiarid regions of Spain. Table grape vineyards encompassed 19,500 ha in Spain, second in Europe behind Italy (OIV 2006). 82\% of the vineyards are irrigated (Anuario de Estadística Agroalimentaria 2008).

Due to the scarcity of water in semiarid areas, estimation of crop water requirements (i.e. evapotranspiration, ET) is paramount. Seasonal ET depends upon environmental conditions, characteristics of the crops (such as trellis system and row spacing in vineyards), and cultural practices (such as canopy and irrigation management). Seasonal table grape $E T$ has been reported to range from 687 to 1,350 mm (Williams et al. 2003; Williams and Ayars 2005a; Netzer et al. 2009; Rodríguez et al. 2010). Different techniques have been used to measure or to estimate table grape ET and crop coefficients: weighing lysimeters (Williams and Ayars 2005a; Williams et al. 2003), drainage lysimeters (Vieira de Azevedo et al. 2008; Netzer et al. 2009), Bowen ratio (Rana et al. 2004; Texeira et al. 2007), and eddy covariance (Rodríguez et al. 2010).

Crop evapotranspiration $\left(E T_{\mathrm{c}}\right)$ is often estimated by multiplying reference crop evapotranspiration $\left(E T_{\mathrm{o}}\right)$ by a crop coefficient $\left(K_{\mathrm{c}}\right): E T_{\mathrm{c}}=K_{\mathrm{c}} \times E T_{\mathrm{o}}$ (Allen et al. 1998). The factors determining the $K_{\mathrm{c}}$ are stage of crop growth, canopy height, local climate, architecture and cover, and crop management among others. Allen et al. (1998) 
presented procedures to estimate the $K_{\mathrm{c}}$ as a single crop coefficient or as a dual crop coefficient, i.e. as the sum of two components, basal crop coefficient $\left(K_{\mathrm{cb}}\right)$ due to transpiration, and evaporation coefficient $\left(K_{\mathrm{e}}\right)$ due to soil evaporation.

It has been also suggested to multiply the $K_{\mathrm{c}}$ by an additional factor $K_{\mathrm{r}}$ to reduce the $K_{\mathrm{c}}$ if ground cover is below some threshold value, for instance 50-60\% (Fereres and Castel 1981; Fereres et al. 1981) or $75 \%$ (Williams and Ayars 2005a). Below these threshold values, $K_{\mathrm{r}}$ is computed as a function of ground cover. Allen and Pereira (2009) also presented a general procedure to adjust $K_{\mathrm{c}}$ as a function of ground cover that is based in the guidelines outlined by Allen et al. (1998). Accordingly, $K_{\mathrm{c}}$ for table grape vineyards for the initial, mid-season, and end-season stages would be 0.30, 0.95, and 0.75 for an effective ground cover of $50 \%$, and 0.30 , 1.10 , and 0.85 for an effective ground cover of $70 \%$ (Allen and Pereira 2009). Pruning and trellis system have also been reported to modify the $K_{\mathrm{c}}$ (Williams and Ayars 2005a).

Williams et al. (2003) and Williams and Ayars (2005a) reported mid-season $K_{\mathrm{c}}$ values for Thompson Seedless grapevines in California under a head training system ranging from about $0.90-1.30$ when ground cover ranged from 60 to $75 \%$. These authors found that $K_{\mathrm{c}}$ showed a better linear relationship with ground cover than with LAI. Rodríguez et al. (2010) reported mid-season $K_{\mathrm{c}}$ values of 0.59 for a ground cover of about $62 \%$ for Perlette and Superior grapevines trained to " $Y$ " trellis. Netzer et al. (2009), for Superior Seedless grapevines trained to an open-gable trellis system, reported that $K_{\mathrm{c}}$ was 0.4 about 15 days after budbreak, and increased to $0.8-0.9$ (veraison), 1.1-1.2 (harvest), and a maximum of about 1.3 (end of September). Netzer et al. (2009) argued that this increase in $K_{\mathrm{c}}$ during late season was the result of the increase in canopy size even after veraison due to the trellis system and the similarity among $E T_{\mathrm{c}}$ and $E T_{\mathrm{o}}$ values during summer and fall.

In the recent years, the use of plastic mulching and netting has extended. The black plastic mulching reduces evapotranspiration from 10 to $30 \%$ due to the combined effect of increasing transpiration by $10-30 \%$ and decreasing soil evaporation by $50-80 \%$ (Allen et al. 1998). The netting made of insect-proof nets is widely used to decrease pesticide applications, radiative load during summer, and damage by hail and birds. The netting has a relatively low cost compared with total production costs in these vineyards; however, it might have an important effect on microclimate and crop water requirements. For instance, a $38 \%$ reduction in crop evapotranspiration due to reduced incoming solar radiation and wind speed was reported for sweet pepper (Möller and Assouline 2007).
There is little information about table grape $E T_{\mathrm{c}}$ and $K_{\mathrm{c}}$ under these two management systems, black plastic mulching and netting. Rana et al. (2004) studied the effects of different types of netting (uncovered, thin net, and thin plastic film) on table grape ET (cv. Italia) with a head training system and complete ground cover. Reported midseason $K_{\mathrm{c}}$ values for unstressed table grape vineyards were 1.0 for the uncovered vineyard, 0.9 for the thin net cover, and 0.86 for the thin plastic film. These values must not be considered $K_{\mathrm{c}}$ as defined by Allen et al. (1998) but as 'adjusted' $K_{\mathrm{c}}$ taking into account the effects of the netting.

This research was conducted to measure the evapotranspiration of a table grape vineyard (Vitis vinifera $\mathrm{L}$. cv. 'Red Globe') grown under the semiarid conditions of the central Ebro River Valley in Spain. This vineyard was trained to a gable trellis and grown under netting with black plastic mulch covering the soil directly beneath the vine row to minimize soil evaporation. Seasonal crop coefficients were also calculated as a function of both the management practices listed earlier.

\section{Materials and methods}

Site and crop

The study was conducted at the commercial farm Santa Bárbara, in Caspe (Zaragoza, NE Spain) during 2007 (May to October) and 2008 (April to October). The geographical coordinates of the experiment location were $41^{\circ} 16^{\prime} \mathrm{N}$ latitude, $0^{\circ} 1^{\prime} \mathrm{W}$ longitude, and $147 \mathrm{~m}$ elevation above sea level. The long-term average annual meteorological conditions in the area are as follows: precipitation, $315 \mathrm{~mm}$; mean air temperature, $14.9^{\circ} \mathrm{C}$; minimum air relative humidity, $41 \%$; global solar radiation, $185 \mathrm{~W} \mathrm{~m}^{-2}$; wind speed at $2 \mathrm{~m}$ above ground, $3.1 \mathrm{~m} \mathrm{~s}^{-1}$; and reference evapotranspiration, $1,392 \mathrm{~mm}$ (Martínez-Cob and Faci 2010).

The study was conducted in a 1.3 ha commercial table grape (Vitis vinifera L., cv. Red Globe) vineyard located within a larger Red Globe vineyard of 7.0 ha (Fig. 1). The vines were planted in 1999 with vine and row spacings of 2.0 and $3.5 \mathrm{~m}$, respectively $\left(1,400\right.$ vines $\left.\mathrm{ha}^{-1}\right)$. The vineyard had a slope of $2 \%$, and the soil was sandy except for horizon A (upper $0.1-0.2 \mathrm{~m}$ ), which was sandy loam. Row direction was approximately northwest to southeast. The trellis system was a Y-shaped gable and $2.2 \mathrm{~m}$ in height with three foliage wires per cross-arm (Fig. 2). The vines were trained to quadrilateral cordons and pruned to six spurs per cordon leaving 2-3 buds per spur. Other table grape vineyards and orchards surrounded this vineyard.

The vineyard was covered with high-density polyethylene having individual pores of $12 \mathrm{~mm}^{2}(2.2 \times 5.4 \mathrm{~mm})$ to 
Fig. 1 a External view of the vineyard showing the netting. b Ground cover during midseason
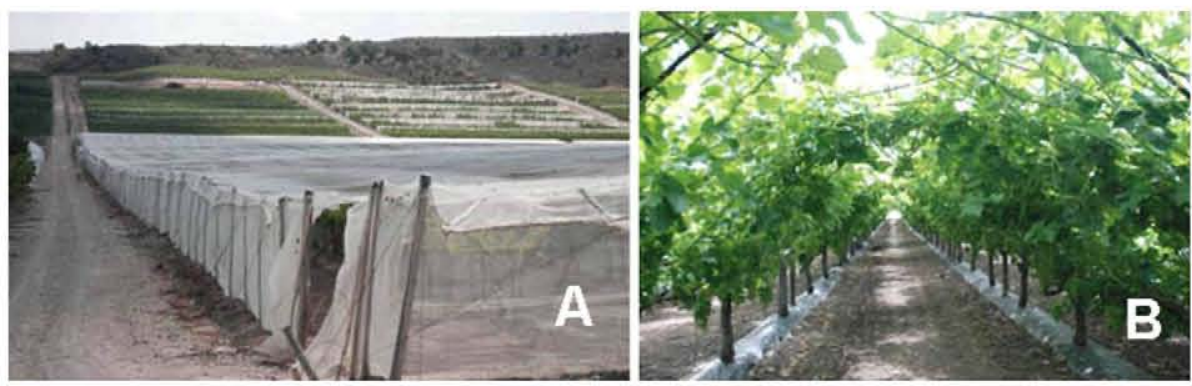

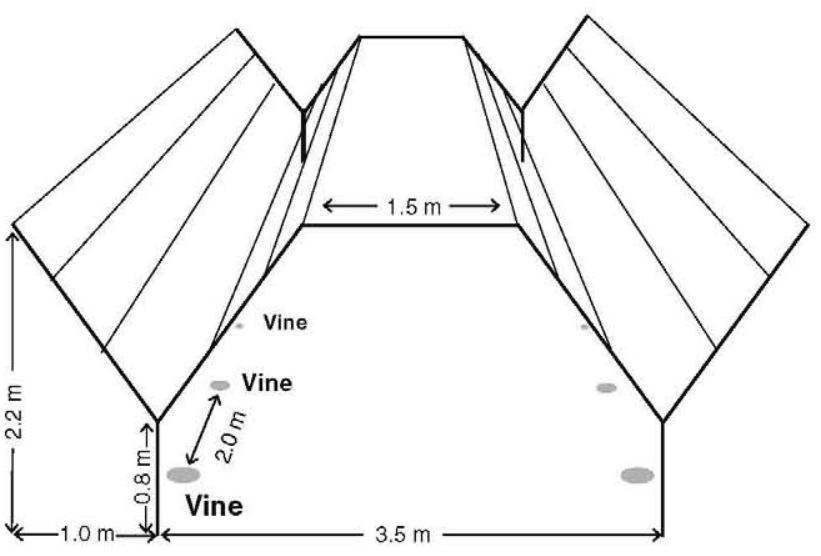

Fig. 2 Dimensions of the Y-shaped gable trellis system under the netting

protect the vines from hail, birds, and insects (Fig. 1a). The netting was positioned slightly higher than the top of trellis system's cross-arms (approximately $2.2 \mathrm{~m}$ above the soil surface). Thus, there was negligible space between the top of the canopy and the netting. Similar netting was used in the other table grape vineyards located in the farm (Fig. 1a).

The ground cover was determined as $G C=1-\left(\mathrm{PAR}_{\mathrm{ss}} /\right.$ $\mathrm{PAR}_{\mathrm{in}}$ ), where $G C$ fraction of ground cover; $\mathrm{PAR}_{\mathrm{ss}}$, average photosynthetically active radiation (PAR) recorded at the soil surface, at a network of 42 points within a rectangle of $7 \mathrm{~m} \times 6 \mathrm{~m}$ that included 8 vines; and $\mathrm{PAR}_{\mathrm{in}}$, the PAR recorded above crop canopy. Readings were taken every 1-2 weeks around solar noon using a SunScan Canopy Analysis System (Delta-T Devices, Cambridge, UK) (Potter et al. 1996) that was placed perpendicular to the rows. For determining $\mathrm{PAR}_{\mathrm{in}}$, two readings were taken just before and just after the $\mathrm{PAR}_{\mathrm{ss}}$ readings.

Directly beneath the vines in each row, a ridge $0.5 \mathrm{~m}$ in width and $0.4 \mathrm{~m}$ in height was established. The vines were drip irrigated, and the lateral line placed on top of the ridge. There were four emitters per vine each with a discharge volume of $2.2 \mathrm{~L} \mathrm{~h}^{-1}$. A volumetric water meter was placed at the inlet of the experimental vineyard $(1.3 \mathrm{ha})$ to register the irrigation depth applied. The ridge and drip line were completely covered with black plastic ( $0.1 \mathrm{~mm}$ thickness) to minimize soil evaporation and control weeds (Fig. 1b).
Daily irrigations from May to September and other management practices (herbicide and fertilizer applications and pruning) were conducted according to the farm manager's criteria. Herbicides were periodically applied between rows to control weeds. Vines were pruned with hydraulic shears in February each year.

Surface renewal and micrometeorological variables measurement

A micrometeorological station was installed in the middle of the vineyard. The surface renewal (SR) method was chosen to determine crop evapotranspiration. Most of the micrometeorological methods used for $E T_{\mathrm{c}}$ determination, such as the eddy covariance method, require that the measurements be made within the inertial sub-layer (Meyers and Baldocchi 2005; Monteith and Unsworth 2008). Möller and Assouline (2007) measured sweet pepper evapotranspiration under netting using an eddy covariance system but there was more than one meter between top canopy and the netting. However, in this study, the quite short distance between the netting and the top of the canopy made it impossible to take measurements within the inertial sub-layer and precluded the use of the eddy covariance and other micrometeorological methods. However, the SR method has already proven its accuracy on a wide range of crops with different canopy architectures and management conditions (Paw U et al. 2005 ). Since the SR method to determine $E T_{\mathrm{c}}$ has also been successfully used over different crops (including grapevine) within the roughness sub-layer (Castellví and Martínez-Cob 2005; Castellví et al. 2006, 2008; Spano et al. 2008; Castellví and Snyder 2009, 2010), it was employed here.

The SR method is based on the presence of ramp-like structures in the high-frequency readings of air temperature (Paw U et al. 1995, 2005). SR analysis assumes that an air parcel suddenly moves downward into the canopy where it remains for a period of time exchanging heat and mass with the canopy elements, until the parcel is ejected upwards and replaced by another air parcel sweeping in from aloft. While in contact with the surface, the air parcel is heated (or cooled) because of heat exchange between the air and the canopy elements (Paw U et al. 1995, 2005). These temperature changes can be characterized by two 
parameters: amplitude $(A)$ and inverse ramp frequency $(\tau)$ (Paw U et al. 1995, 2005; Snyder et al. 1996; Spano et al. 2000a). Knowing these two parameters, the sensible heat flux $(H)$ is estimated as follows:

$H=(\alpha z) \rho C_{\mathbf{p}} \frac{A}{\tau}$

where $\alpha$ is a weighting factor; $\rho$ is the density of air $\left(\mathrm{kg} \mathrm{m}^{-3}\right) ; C_{\mathrm{p}}$ is the specific heat capacity of air at constant pressure $\left(\mathrm{J} \mathrm{kg}^{-1}{ }^{\circ} \mathrm{C}^{-1}\right) ; z$ is the measurement height $(1.9 \mathrm{~m})$; and $\frac{A}{\tau}$ is the rate of change in air temperature $\left({ }^{\circ} \mathrm{C} \mathrm{s}^{-1}\right)$. The value of $\alpha$ depends on the crop roughness, the measurement height, and atmospheric stability conditions. According to Paw $\mathbf{U}$ et al. (2005), $\alpha$ is a calibration factor initially estimated as 0.5 to account for a linear change in temperature with height. However, uneven heating within the canopy leads to different $\alpha$ values (Paw $\mathbf{U}$ et al. 1995; Snyder et al. 1996; Spano et al. 1997a, b; Duce et al. 1997). Generally, for near-neutral conditions, $\alpha=0.5$ was reported over mixed deciduous forest, walnut orchard, and maize canopies (Paw $U$ et al. 1995). For a short turf grass, good estimates of $\mathrm{H}$ were obtained using $\alpha=1$, when the measurements were taken in the inertial sub-layer for average conditions (Snyder et al. 1996). Values of $\alpha$ have been reported to range between 0.23 for citrus (Snyder and O'Connell 2007) and 1.88 for bare soil (Duce et al. 1998).

For grape vineyard with $2.0-2.2 \mathrm{~m}$ height and about $60 \%$ ground cover, at different locations of California and Italy, reported $\alpha$ values in vineyards have ranged from 1.04 to 0.65 for measurement heights ranging from 1.75 to $2.9 \mathrm{~m}$ above the soil surface, respectively (Spano et al. 1997a, 2000b). Thus, for crops with characteristics similar to those in this study, it can be assumed that $\alpha$ varies between 0.6 and 1.0 (Spano et al. 1997a; Mengistu and Savage 2010).

Generally, appropriate values of $\alpha$ are obtained by comparing $H$ values estimated with the surface renewal method and $H$ values measured with the eddy covariance micrometeorological method (Snyder et al. 1996; Spano et al. 1997b). However, it was not possible to use the eddy covariance method in this study as explained earlier. Therefore, based in the reported $\alpha$ values for table grapes and other crops with relatively similar canopy architecture to that in this experiment, the values of $\alpha=0.6$ and $\alpha=1.0$ were examined in this study and used in Eq. 1 .

The SR method used high-frequency air temperature values that were recorded every $0.2 \mathrm{~s}$ using two chromelconstantan thermocouples of $72 \mu \mathrm{m}$ diameter (Campbell Scientific, model TCBR-3) placed $1.9 \mathrm{~m}$ above the top of the ridges. High-frequency air temperature values were later analyzed as described in "Appendix" to estimate A and $\tau$ for each half-hour for both thermocouples and four time intervals $(0.2,0.4,0.6$, and $0.8 \mathrm{~s})$. Eq. 1 was then used to obtain values of $H$ each half-hour. The $H$ values for the different time intervals and thermocouples were averaged to get two average values of $H$ for each half-hour: one for $\alpha=0.6$ and the other for $\alpha=1.0$.

The micrometeorological station also had a net radiometer (Radiation and Energy Balance Systems, model Q-7), four soil heat flux plates (Hukseflux, model HFP01, two located within the row and two midway between two consecutive rows), a pyranometer (Kipp and Zonen, CM3), a switching anemometer (Vector Instruments, A100R), and an air temperature and relative humidity probe (Vaisala, model HMP45C). Likewise, an infrared thermometer (Apogee, model IRTS-P) was installed perpendicular to the soil surface facing down to the vines from mid-July to midOctober 2007. All sensors but the soil heat flux plates were installed at about $2.1-2.2 \mathrm{~m}$ above the top of the ridges, just below the netting. Net radiometer was placed above the vines but perpendicular to the rows so it also was partially above the soil surface. Soil heat flux plates were buried at about $0.1 \mathrm{~m}$ from the soil surface. Half-hourly averages of net radiation $\left(R_{\mathrm{n}}\right)$, soil heat flux $(G)$, incoming global solar radiation, wind speed, air temperature and relative humidity, and canopy temperature were obtained. In the case of soil heat flux, the 30-min values of $G$ were the mean values of the four soil heat flux readings (Allen et al. 1996). Latent heat flux ( $L E, \mathrm{~W} \mathrm{~m}^{-2}$ ) was obtained each half-hour for both values of $\alpha$, by solving the energy balance equation:

$L E=R_{\mathrm{n}}-G-\mathrm{H}$

Daily values of table grape evapotranspiration $\left(E T_{\mathrm{c}}\right.$, $\mathrm{mm} \mathrm{day}^{-1}$ ) were obtained by averaging the corresponding half-hour values of $L E$ and dividing by the latent heat of vaporization, estimated as described by Ham (2005). Subsequently, additional statistics were calculated to measure the difference between both sets of $E T_{\mathrm{c}}$ values, using $\alpha=0.6$ and 1.0. These statistics were the mean estimation error (MEE), the root mean square error (RMSE), and the systematic mean square error $\left(\mathrm{MSE}_{\mathrm{s}}\right)$ (Willmott 1982).

\section{Crop coefficicient}

Daily values of the vineyard crop coefficient $\left(K_{\text {cexp }}\right)$ were derived from the ratio of the daily measured $E T_{\mathrm{c}}$ (average of the two $E T_{\mathrm{c}}$ values obtained using both $\alpha$ values) and the daily estimated $E T_{\mathrm{o}}$, computed using the FAO PenmanMonteith method (Allen et al. 1998) from the daily meteorological variables (wind speed, solar radiation, air temperature, and relative humidity) recorded at a standard weather station located over grass following Allen et al. (1998) guidelines about $1 \mathrm{~km}$ north from the vineyard 
('grass station'). This station belongs to a network named SIAR installed and managed by the Spanish Ministry of Rural and Marine Environment (http://www.mapa.es/siar/).

$K_{\text {cexp }}=\frac{E T_{\mathrm{c}}}{E T_{\mathrm{o}}}$

It should be noted that these $K_{\text {cexp }}$ values are adjusted crop coefficients that take into account the effect of the netting and the black plastic mulching. It was assumed that these two management practices would reduce vineyard $E T$ and the $K_{\mathrm{c}}$ compared with a similar vineyard managed without those practices. Thus, these $K_{\text {cexp }}$ values would represent the optimum (potential) evapotranspiration of the crop under these management practices.

During mid-July to mid-October 2007, the cumulative stress-degree-day (SDD) (Kirkham 2005) was computed as follows to detect possible water stress in the crop:

$\mathrm{SDD}=\sum_{\mathrm{i}=1}^{N}\left(T_{\mathrm{c}}-T_{\mathrm{a}}\right)_{\mathrm{i}}$

where $T_{\mathrm{c}}$ is the canopy temperature measured with the infrared thermometer $\left({ }^{\circ} \mathrm{C}\right), T_{\mathrm{a}}$ is the air temperature $\left({ }^{\circ} \mathrm{C}\right)$, and $N$ is the number of days used to compute SDD. For each particular day i, $T_{\mathrm{c}}$ and $T_{\mathrm{a}}$ were the averages of these variables between 13:00 and 15:00 as suggested by Kirkham (2005). If a crop is well watered and transpiring to an optimal rate, the cumulative SDD should be close to 0 or negative.

The table grape vineyard crop coefficients were also estimated following the dual $K_{\mathrm{c}}$ approach by Allen et al. (1998) but with adjustments to take into account the presence of the netting and the black plastic mulching. Using this approach, $K_{\mathrm{c}}$ is estimated as the sum of two components, basal crop coefficient $\left(K_{\mathrm{cb}}\right)$ due to transpiration and evaporation coefficient $\left(K_{\mathrm{e}}\right)$ due to soil evaporation. Three $K_{\mathrm{cb}}$ values must be computed to get the $K_{\mathrm{cb}}$ curve along the crop season: initial, mid-season, and endseason. The initial $K_{\mathrm{cb}}\left(K_{\mathrm{cb} \_ \text {ini }}\right)$ was assumed to be 0.1 to take into account the effect of the mulching (Allen et al. $1998)$. The mid- and end-season $K_{\mathrm{cb}}\left(K_{\mathrm{cb} \_ \text {mid }}\right.$ and $\left.K_{\mathrm{cb} \_ \text {end }}\right)$ were first estimated from tabulated values for an effective ground cover of $75 \%$ (Allen and Pereira 2009): 1.05 $\left(K_{\text {cb_mid }}\right)$ and $0.80\left(K_{\text {cb_end }}\right)$, which were higher than those tabulated values by Allen et al. (1998) which correspond to an effective ground cover of $50 \%$. Next, the tabulated $K_{\text {cb mid }}$ and $K_{\text {cb end }}$ were adapted to local climatic conditions using the average wind speed and minimum relative humidity recorded at the nearby 'grass station' during the mid- and end-season stages. Later, the locally adapted $K_{\mathrm{cb} \_ \text {mid }}$ and $K_{\mathrm{cb} \text { end }}$ were multiplied by two coefficients to take into account the effects of the black plastic mulching $\left(K_{\mathrm{mu}}\right)$ and the netting $\left(K_{\mathrm{ne}}\right)$. Allen et al. (1998) argued that the black plastic mulching increases transpiration while decreasing soil evaporation leading to a combined effect of reduced evapotranspiration. They recommended to use a broad value of $K_{\mathrm{mu}}=0.9$ when using the dual crop coefficient approach.

Regarding to the $K_{\text {ne }}$, no much information was available to estimate it. However, as a first approximation, the seasonal averages (April to October 2007 and 2008) of the daily incoming solar radiation, wind speed, and air temperature and relative humidity recorded below the netting at the micrometeorological station were divided by the corresponding seasonal averages of the daily values recorded at the nearby 'grass station'. These ratios were assumed to represent the microclimatic effect due to the netting. Later, the recorded daily values of the above-mentioned meteorological variables were multiplied by those ratios and used to get approximate estimates of $E T_{\mathrm{o}}$ 'under the netting' using the FAO Penman-Monteith method (Allen et al. 1998). Thus, the ratio of average $E T_{\mathrm{o}}$ 'under the netting' to average $E T_{\mathrm{o}}$ using the originally recorded meteorological variables at the 'grass station' was used as a first approximation of the evapotranspiration reduction induced by the netting and thus as a rough estimation of $K_{\text {ne }}$.

The coefficient due to soil evaporation $K_{\mathrm{e}}$ was estimated according to Allen et al. (1998). However, it was assumed that the fraction of soil wetted and exposed to the sun was 0 due to the black plastic mulching. No other adjustment was done as the procedure by Allen et al. (1998) computes $K_{\mathrm{e}}$ basically as a function of the soil moisture in the upper soil layer $(0.1 \mathrm{~m})$ defining two limits, readily (REW) and total evaporable water (TEW), as a function of soil texture, field capacity, and wilting points. These parameters, obtained from soil samples in the upper soil layer, allowed estimating REW and TEW as 4.0 and $12.4 \mathrm{~mm}$, respectively, for this work.

Thus, the daily values of estimated crop coefficient $\left(K_{\mathrm{cFAO}}\right)$ were obtained for 2007 and 2008 as the sum of the adjusted $K_{\mathrm{cb}}$ and $K_{\mathrm{e}}$ values. These estimates were assumed to represent the values that would be computed for a vineyard grown under the netting with black plastic mulch, using the procedure described by Allen et al. (1998). These estimates provided a gross, general approximation for this crop management situation, and they were compared to the measured $K_{\text {cexp }}$ values.

\section{Results and discussion}

The crop phenological development was similar for both years of the study (Table 1). This type of vineyard with this trellis system typically reaches a high ground cover fraction, about $90 \%$ at 100 days after budbreak (DAB) (Fig. 3). Additional crop growth was observed after that date but was not quantified. 
Table 1 Phenology of Red Globe grapevines during 2007 and 2008 growing seasons

\begin{tabular}{lllll}
\hline Years & Budbreak & Berry set & Veraison & Harvest \\
\hline 2007 & March 10 & June 6 & July 24 & September 13 \\
& $(0)$ & $(88)$ & $(136)$ & $(187)$ \\
2008 & March 12 & June 11 & July 25 & September 10 \\
& $(0)$ & $(91)$ & $(135)$ & $(182)$ \\
\hline
\end{tabular}

Values within parentheses denote days after budbreak (DAB)

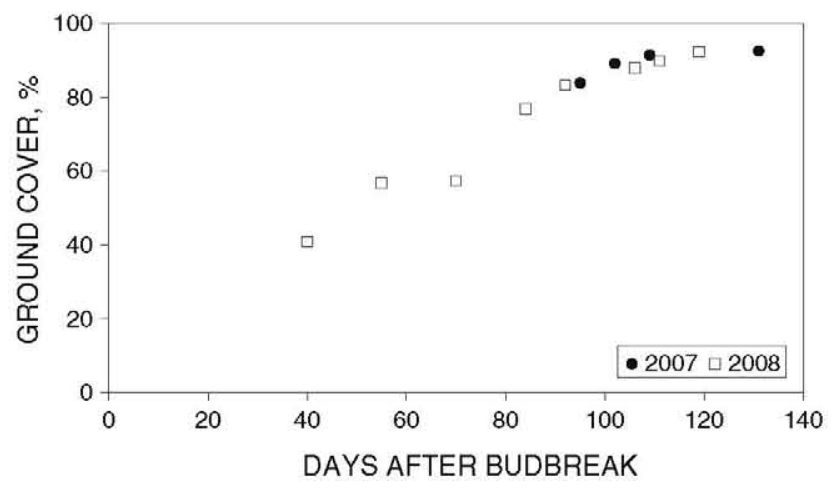

Fig. 3 Progression of ground cover during the growing season. Budbreak (day 0) occurred on March 10, 2007 and March 12, 2008

There were slight differences in the meteorological conditions between years (Fig. 4). The year 2008 was more humid and cooler than 2007, and precipitation from April to October was somewhat greater in $2008(253 \mathrm{~mm})$ than in $2007(194 \mathrm{~mm})$. The largest difference in precipitation between years was recorded during October: about $8 \mathrm{~mm}$ of rain in 2007 and about $44 \mathrm{~mm}$ of rain in 2008 (Fig. 4).

Although spring 2008 was cooler than spring 2007, air temperatures were relatively similar in both years for the rest of the season. Accordingly, the highest differences between years for vapor pressure deficit were also noticed during spring, which was higher for 2007 . The average wind speeds were similar in both years except for higher wind speeds recorded during April 2008. In general, weather variability was greater in 2007. Lastly, estimates of $E T_{\mathrm{o}}$ were lower during the summer and fall in 2008 due to the higher precipitation and lower vapor pressure deficit and wind speed compared with 2007 (Fig. 4).

The total seasonal irrigation depth was slightly higher in $2007(778 \mathrm{~mm})$ than in $2008(750 \mathrm{~mm})$ due to the abovementioned meteorological conditions (Table 2). Irrigation was applied according to farm's manager criteria. The cumulative SDD for the period mid-July to mid-October (Fig. 5) indicated that the vines used in this study were not stressed for water (Kirkham 2005). In fact, the cumulative SDD suggests that some overirrigation of the vineyard may have occurred. No SDD data were available for 2008 . However, the seasonal irrigation depth was only slightly lower than that of 2007 due to the cooler and more humid meteorological conditions. Therefore, it can be assumed that the crop was not under water stress, and thus, measured crop evapotranspiration could be assumed as optimal under the management conditions of this experiment, the netting and black plastic mulching.

Figure 6 shows the half-hourly values of the amplitudes of the temperature ramps computed for a 5-day period for
Fig. 4 Weekly meteorological conditions during 2007 and 2008 recorded at a standard weather station over grass located $1 \mathrm{~km}$ from the vineyard. a Precipitation; b mean air temperature; $\mathbf{c}$ mean vapor pressure deficit; and $\mathbf{d}$ mean wind speed at $2.0 \mathrm{~m}$ above ground. Budbreak (day 0) occurred on March 10, 2007 and March 12, 2008
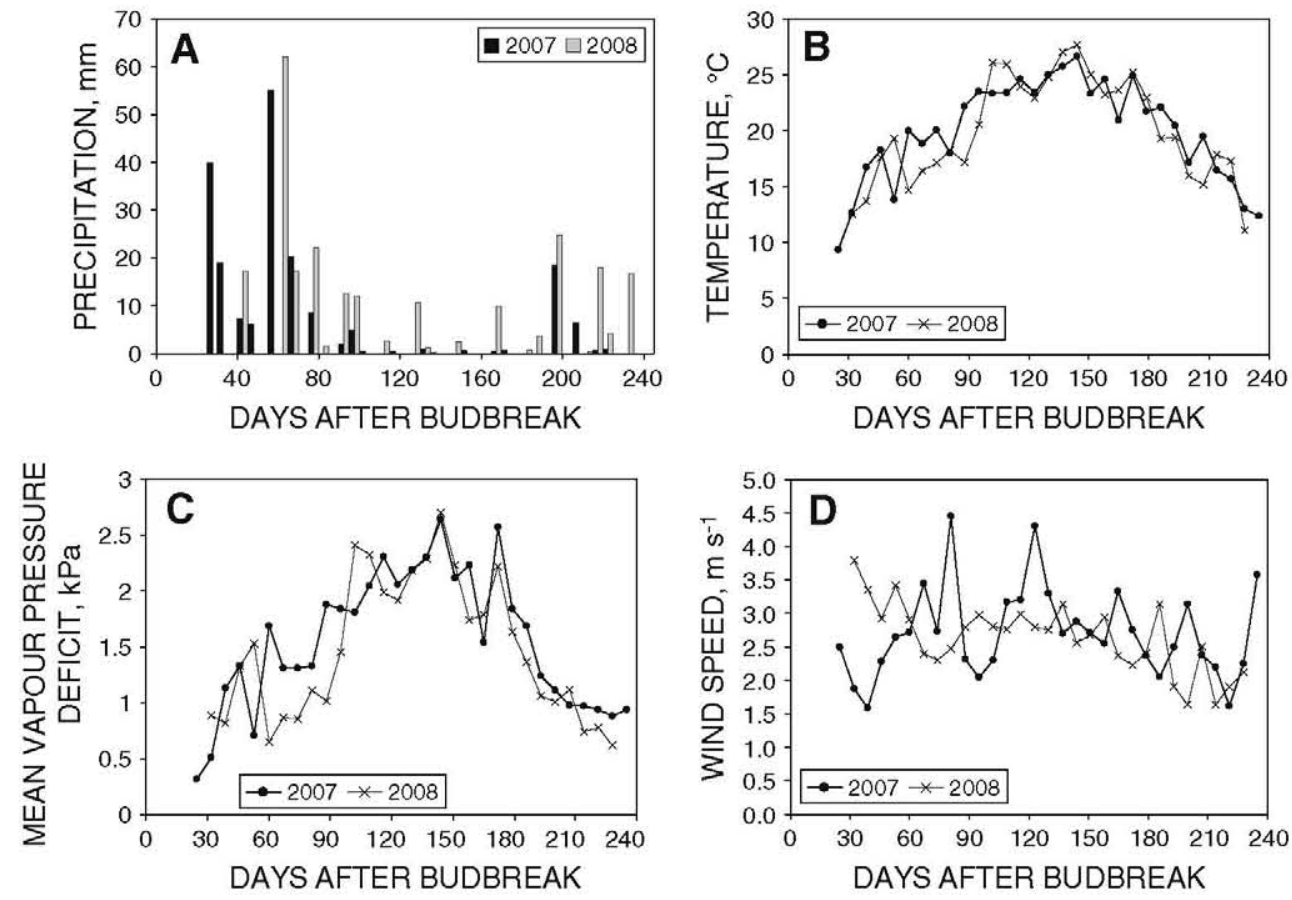
Table 2 Monthly irrigation water amounts ( $\mathrm{mm}$ ) applied during the 2007 and 2008 growing seasons for the Red Globe vineyard

\begin{tabular}{lccrcccc}
\hline Years & Apr & May & Jun & Jul & Aug & Sep & Oct \\
\hline 2007 & 35.4 & 67.3 & 108.4 & 163.3 & 182.9 & 135.8 & 84.7 \\
2008 & 45.2 & 61.9 & 89.7 & 149.9 & 217.2 & 131.5 & 54.6 \\
\hline
\end{tabular}

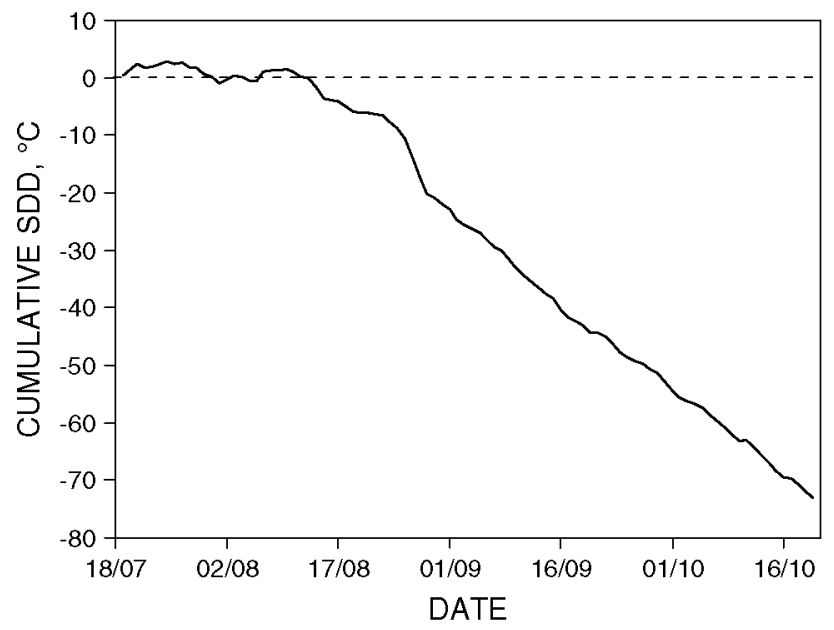

Fig. 5 Cumulative stress-degree-days (SDD) from mid-July to midOctober 2007

2007 and 2008 for two of the time lags ( 0.4 and 0.6 s) used in this work. In general terms, these values were representative of the amplitudes obtained for the remaining measurement periods and for the other two time lags $(0.8$ and $0.2 \mathrm{~s}$ ). It can be seen that amplitudes during nighttime periods were negative and relatively close to 0 , indicating low sensible heat flux as expected during these periods. During unstable periods (daytime), amplitudes showed a well-defined pattern, continuously increasing until midday as a consequence of warmer canopy surface heating surrounding air, and a later decrease as canopy surface was becoming cooler than air and now sensible heat flux was becoming smaller. These results suggest that the SR method was able to detect the ramp-like temperature traces produced in this vineyard. In this particular case, it should be expected that these ramps were primarily the result of thermal turbulence as the presence of the netting also highly reduced wind speeds and therefore mechanical turbulence.

It was not possible to obtain an appropriate $\alpha$ value by comparing $H$ obtained with the SR method against $H$ measured with the eddy covariance method. But the results of Fig. 7 and Table 3 indicate that finding the appropriate $\alpha$ value was not important as the $E T_{\mathrm{c}}$ values obtained using Eq. 2 were only slightly affected by the chosen $\alpha$ value to get $H$. Thus, both sets of $E T_{\mathrm{c}}$ values were highly correlated with one another, the MEE was $<0.07 \mathrm{~mm} \mathrm{day}^{-1}$, the
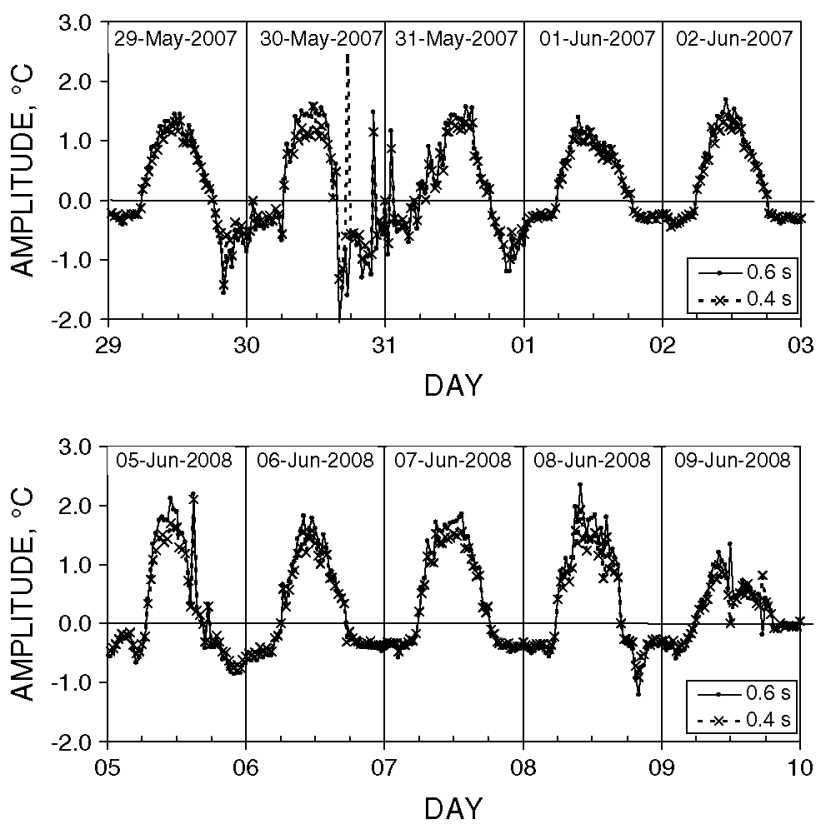

Fig. 6 Half-hour values of the amplitudes of the temperature ramps computed for five selected days in 2007 and 2008

RMSE was less than $0.270 \mathrm{~mm} \mathrm{day}^{-1}$, the ratio of means, $\bar{y} / \bar{x}$, suggested a very low average difference (less than $1.6 \%$ ), and the systematic MSE (MSE ) was $^{2} 16 \%$ for data each year and both years combined (Table 3 ). Because of the very slight effect of the $\alpha$ used to get $\mathrm{H}$ on the daily $E T_{\mathrm{c}}$ values obtained, both sets of $E T_{\mathrm{c}}$ values were averaged to get experimental crop coefficients $\left(K_{\text {cexp }}\right)$ adjusted for the netting and the black plastic mulching using Eq. 3.

In irrigated systems, $H$ is often small, as most part of the net radiation is converted into latent heat flux (ET). Therefore, the accuracy of the $E T$ values obtained using the energy balance closure will depend largely on the accuracy of the net radiometer used. The monthly averages of the half-hour values of the energy balance components, $L E$, $H$ (average of values calculated with both $\alpha$ ), $R_{\mathrm{n}}$, and $G$, obtained in this work for 2007 are plotted in Fig. 8. The results for 2008 were similar. The data from Fig. 8 clearly illustrate the low proportion of $H$ when compared to $R_{\mathrm{n}}$, and the decrease in the ratio of $H / R_{\mathrm{n}}$ (for daytime periods) from 0.24 to 0.26 in April-May to about 0.05 in August, and a later increase up to $0.16-0.20$ in October. This change of the ratio of $H / R_{\mathrm{n}}$ was due to the increase in the ground cover fraction and thus, the decrease in thermal turbulence.

Both the measured $E T_{\mathrm{c}}$ and calculated $E T_{\mathrm{o}}$ displayed similar trends across the seasons, increasing from spring to mid-summer and decreasing thereafter (Fig. 9). Average daily $E T_{\mathrm{c}}$ and $E T_{\mathrm{o}}$ from mid-June to mid-September (90-180 days after budbreak) were 5.3 and $7.2 \mathrm{~mm}$ day $^{-1}$, respectively, in 2007 and 5.2 and $6.9 \mathrm{~mm} \mathrm{day}^{-1}$, 


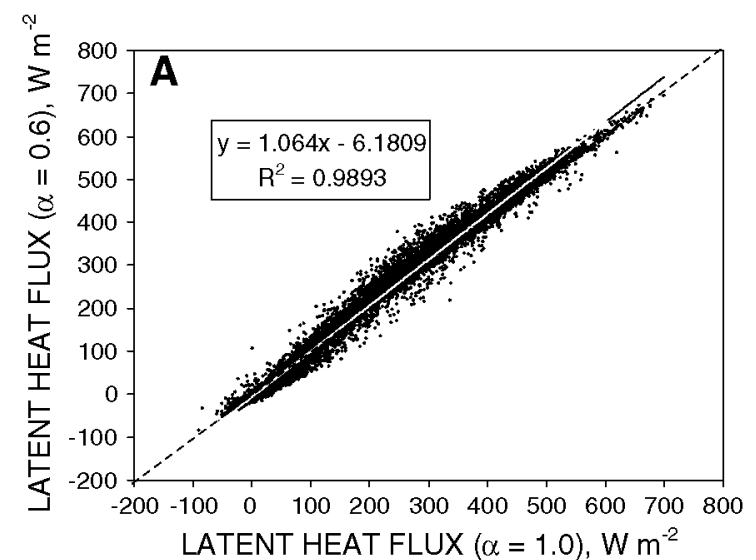

Fig. 7 Correlations of a half-hourly values of latent heat flux for $\alpha=0.6$ versus $\alpha=1.0$ and daily values of evapotranspiration; and b for $\alpha=0.6$ versus $\alpha=1.0$ using all the data from 2007 and 2008 .

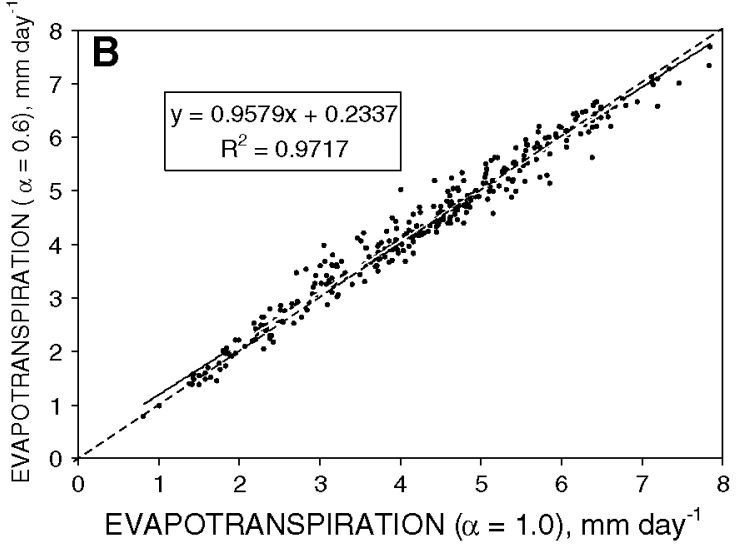

The solid lines represent the linear regression obtained in both cases, the dashed lines represent the straight line $y=x$

Table 3 Error analysis statistics computed for comparison between daily $E T_{\mathrm{c}}$ obtained using $\alpha=0.6$ and using $\alpha=1.0$ for estimating $H$

\begin{tabular}{lllllllc}
\hline Years & $n$ & $\bar{x}\left(\mathrm{~mm} \mathrm{day}^{-1}\right)$ & $\bar{y}\left(\mathrm{~mm} \mathrm{day}^{-1}\right)$ & $\bar{y} / \bar{x}$ & ${\text { MEE }\left(\mathrm{mm} \mathrm{day}^{-1}\right)}$ & RMSE $\left(\mathrm{mm} \mathrm{day}^{-1}\right)$ & MSEs $(\%)$ \\
\hline 2007 & 151 & 4.47 & 4.54 & 1.016 & 0.07 & 0.223 & 0.7 \\
2008 & 188 & 4.13 & 4.17 & 1.009 & 0.04 & 0.270 & 16.0 \\
Both & 339 & 4.28 & 4.33 & 1.013 & 0.05 & 11.0 \\
\hline
\end{tabular}

$n$ Sample size, $\bar{x}$ mean of variable $x\left(E T_{\mathrm{c}}\right.$ for $\left.\alpha=1.0\right), \bar{y}$ mean of variable $y\left(E T_{\mathrm{c}}\right.$ for $\left.\alpha=0.6\right)$; $M E E$ mean estimation error, $R M S E$ root mean square error, $M E S_{\mathrm{s}}$ systematic mean square error

respectively, in 2008. Both $E T_{\mathrm{o}}$ and $E T_{\mathrm{c}}$ were slightly lower during 2008 due to the lower vapor pressure deficit and lower wind speeds compared with 2007 (Fig. 4). The highest daily average for an individual week occurred in July: $6.1 \mathrm{~mm} \mathrm{day}^{-1}$ in 2007 and $6.7 \mathrm{~mm} \mathrm{day}^{-1}$ in 2008 for $E T_{\mathrm{c}}$, and 8.4 and $8.2 \mathrm{~mm} \mathrm{day}^{-1}$ in 2007 and 2008 , respectively, for $E T_{0}$. Williams et al. (2003), and Williams and Ayars (2005a) reported average values of $E T_{\mathrm{c}}$ between 5 and $6 \mathrm{~mm} \mathrm{day}^{-1}$ for a ground cover of $65 \%$, for the same period as our study (mid-June to mid-September) in California and with an $E T_{\mathrm{o}}$ of about $7 \mathrm{~mm}$ day $^{-1}$.

Netzer et al. (2009) obtained maximum values of $E T_{\mathrm{c}}$ of $8.6 \mathrm{~mm} \mathrm{day}^{-1}$ with a ground cover above $80 \%$ and similar climatic conditions to those in this work. Williams and Ayars (2005a) found a linear relationship between shaded area and the crop coefficients, and between the percentage of shaded area and crop water use. Using that relationship, a $90 \%$ ground cover found in this study would correspond to a maximum $K_{\mathrm{c}}$ of about 1.5 and maximum daily $E T_{\mathrm{c}}$ of $9.8 \mathrm{~mm}$, much greater than that reported here. However, the netting over the trellis system reduced incoming solar radiation (by $15 \%$ ) and wind speed (by $85 \%$ ) so it could be expected that $E T_{\mathrm{c}}$ for these vines would be less than a similar situation without the netting (Rana et al. 2004). In addition, the black plastic mulching also reduces evapotranspiration as reported by Allen et al. (1998). The cumulative $E T_{\mathrm{c}}$ for this vineyard from May 1 to October 31 was $843 \mathrm{~mm}$ in 2007 and $787 \mathrm{~mm}$ in 2008, these values also showing the effects of the netting and the black plastic mulching when compared to values reported in other works (Williams et al. 2003; Williams and Ayars 2005a; Netzer et al. 2009).

The experimental crop coefficient $\left(K_{\text {cexp }}\right)$ values calculated using the $E T_{\text {cexp }}$ data from 2007 to 2008 (70-190 days after budbreak) ranged from 0.7 to 0.9 (Fig. 10). The daily values used to obtain weekly averages showed some variability as indicated by the standard deviations depicted in Fig. 10. However, the corresponding coefficients of variation were generally $<20 \%$. The weekly $K_{\text {cexp }}$ values during June (83-112 days after budbreak) in 2008 were higher than those during the same times frames in 2007. This was probably the result of greater rainfall during these periods in 2008 compared with 2007. It is interesting to note that $K_{\text {cexp }}$ increased at the end of the season, particularly for 2008. This increase in $K_{\mathrm{c}}$ during end-season was also reported by Netzer et al. (2009) and Williams and Ayars (2005b). When $E T_{\mathrm{o}}$ is low, a small energy supply, for instance from canopy or soil, may enable an increase in $K_{\mathrm{c}}$ (Testi et al. 2006). Snyder and O'Connell (2007) showed that the high and variable $K_{\mathrm{c}}$ values in citrus were attributed to a combination of factors related to the rainy/foggy conditions that are typical of the region during fall similar to our conditions. Moreover, the 
Fig. 8 Monthly averages of half-hour values of net radiation, and latent, sensible, and soil heat fluxes obtained for 2007
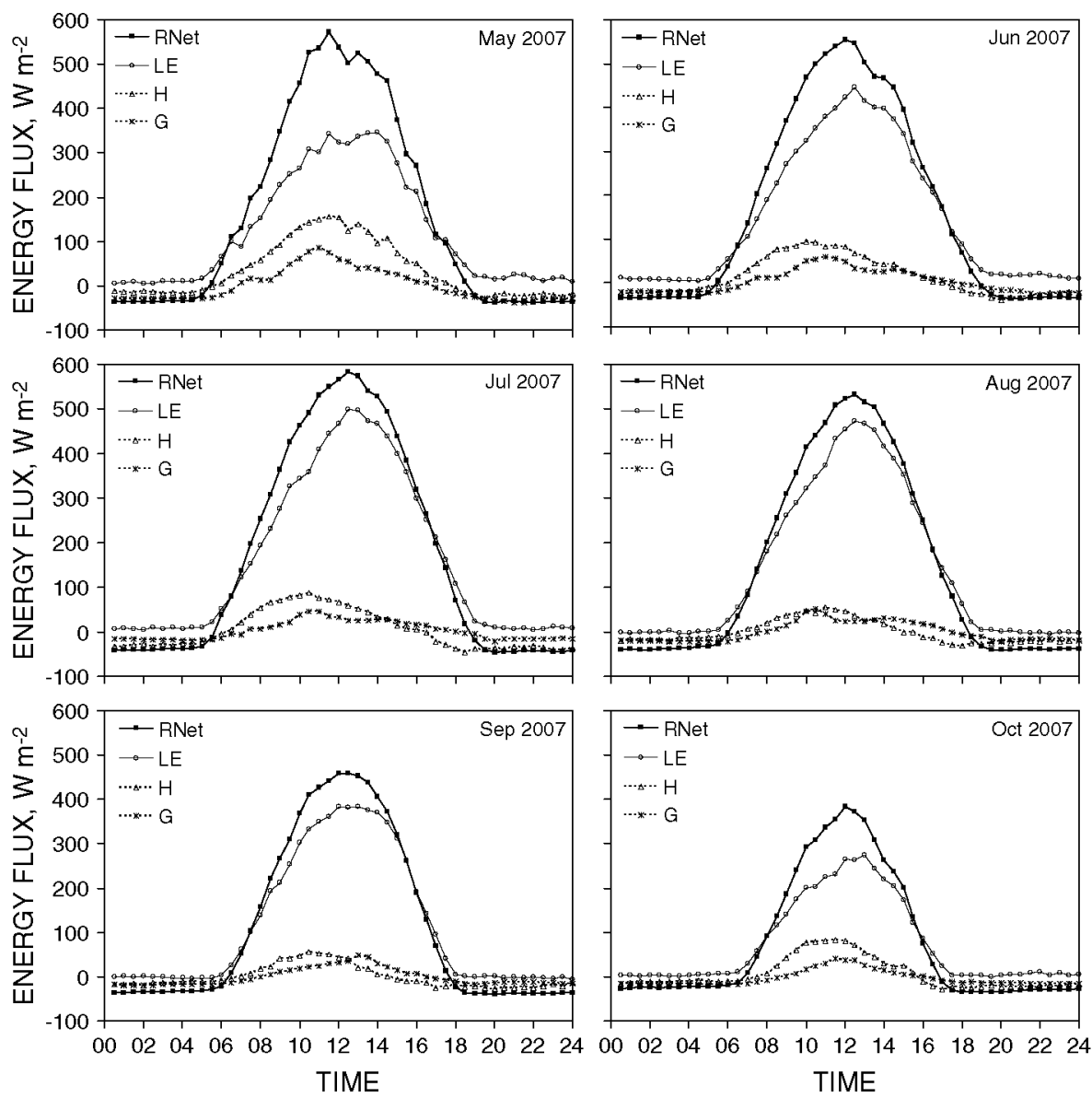
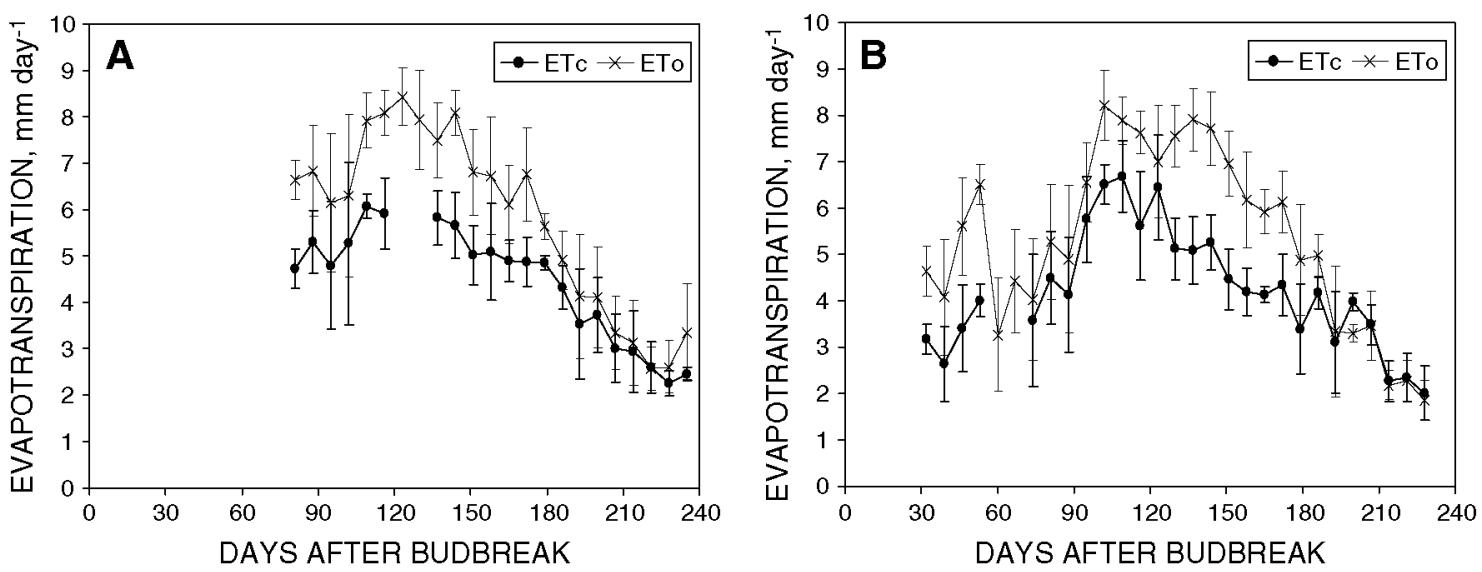

Fig. 9 Weekly measured table grape evapotranspiration $\left(E T_{\mathrm{c}}\right)$ and estimated reference evapotranspiration $\left(E T_{\mathrm{o}}\right.$, grass weather station, method FAO Penman-Monteith). a Weekly averages for 2007 and b weekly averages for 2008. Vertical lines represent one standard deviation

canopy resistance is fixed in the $E T_{\mathrm{o}}$ equation, but the canopy resistance drops when the crop is wetted. This would lead to increased $E T_{\mathrm{c}} / E T_{\mathrm{o}}$. Netzer et al. (2009) argued that the increase in $K_{\mathrm{c}}$ observed during late season was due in part to the crop growth after veraison due to the trellis system, which was similar to the one used in this paper.

In order to compute $K_{\mathrm{CFAO}}$ values, mid-season as defined by Allen et al. (1998) occurred from June 28 in 2007 and
June 18 in 2008 up to September 30 in both years, while end-season occurred until end of October. The averages of wind speed and minimum relative humidity recorded during mid- and end-season in the 'grass station' (Fig. 4) were used to modify the tabulated $K_{\text {cbmid }}$ and $K_{\text {cbend }}$ (Allen and Pereira 2009). Thus, the locally adjusted $K_{\text {cbmid }}$ and $K_{\text {cbend }}$ were estimated to be 1.15 and 0.84 in 2007 and 1.14 and 0.80 in 2008. The ratios of the seasonal averages (April to 

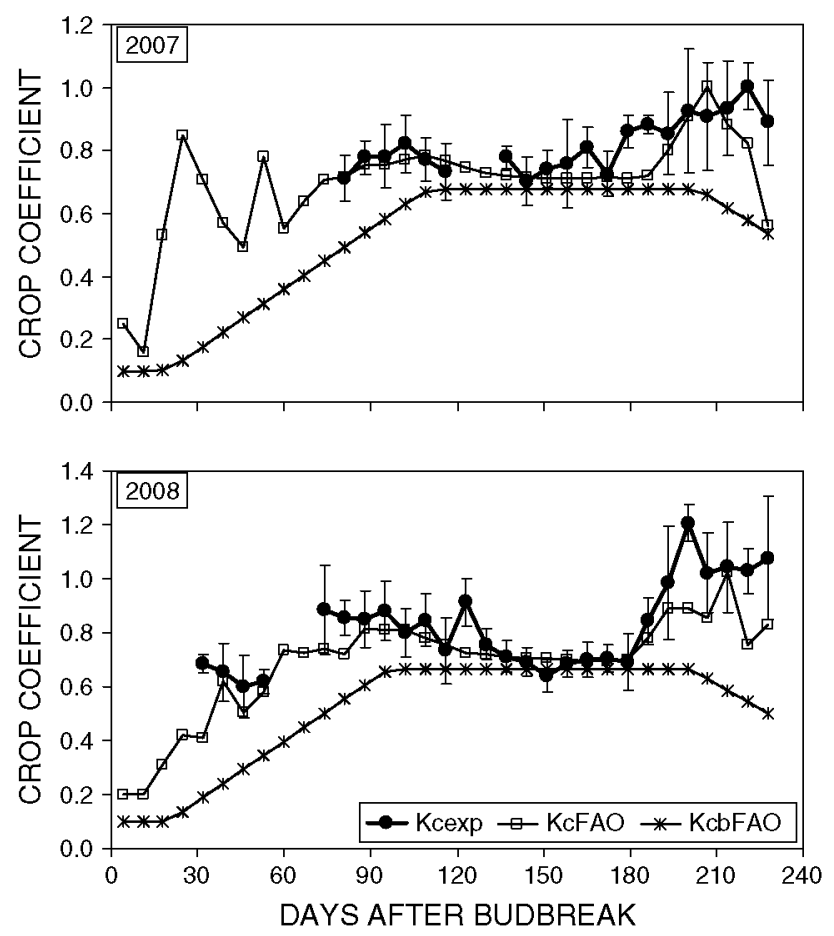

Fig. 10 Weekly values of the experimental table grape crop coefficient $\left(K_{\mathrm{cexp}}\right)$ and estimated total $\left(K_{\mathrm{cFAO}}\right)$ and basal crop coefficient $\left(K_{\mathrm{cbFAO}}\right)$ calculated according to Allen et al. (1998) adjusting for the netting and the plastic mulch. Vertical lines represent one standard deviation

October) of daily values of solar radiation, wind speed, air temperature, and relative humidity recorded at the meteorological station in the vineyard to the corresponding averages recorded in the 'grass station' were $0.855,0.153$, 1.014, and 1.027, respectively. These ratios indicate the important effect of the netting on solar radiation and wind speed and the small effect on air temperature and relative humidity. These ratios were used to modify the recorded meteorological variables to estimate $E T_{\mathrm{o}}$ 'under the netting' using the FAO Penman-Monteith method (Allen et al. 1998). The ratio of the seasonal average $E T_{\mathrm{o}}$ 'under the netting' to that obtained with the originally recorded meteorological variables was 0.65 . According to this ratio, a rough reduction of $35 \%$ in $E T_{\mathrm{o}}$ and thus $E T_{\mathrm{c}}$ could be expected in our conditions by the presence of the netting. This ratio of 0.65 was assumed to be a rough approxima-

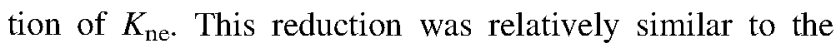
$38 \%$ reduction in sweet pepper ET reported by Möller and Assouline (2007).

Figure 10 also shows the crop coefficients (both total, $K_{\mathrm{cFAO}}$, and basal, $\left.K_{\mathrm{cbFAO}}\right)$ estimated according to the FAO procedure (Allen et al. 1998) but adjusting them to the vineyard management practices studied here, the netting and black plastic mulching. In general terms, both the estimated $K_{\mathrm{cFAO}}$ and the experimental $K_{\text {cexp }}$ crop coefficients followed similar patterns throughout the growing season (Fig. 10). There was a closer agreement during mid-summer when soil evaporation should be smaller due to reduced precipitation and the effect of the black plastic mulching that reduces soil evaporation (in the moistened surface by irrigation) by about $50-80 \%$ according to Allen et al. (1998). The differences observed between $K_{\text {cexp }}$ and $K_{\mathrm{cFAO}}$ reflected in part the uncertainty of estimation of coefficients $K_{\mathrm{mu}}$ and $K_{\mathrm{ne}}$ used in this work, estimation that should require further investigation to improve its accuracy. Possible variability of these coefficients due to such factors as color of the plastic mulching or the time of the year needs more study. Figure 10 also shows that $K_{\mathrm{CFAO}}$ values increased in early fall. In this case, this increase was completely due to the effect of precipitation that moistened soil surface between crop rows, leading to an increase in $K_{\mathrm{e}}$ coefficients. Thus, Allen and Pereira (2009) stated that actual crop coefficient may increase to 1.2 following precipitation even if the estimated basal crop coefficient is small due to surface evaporation from among sparse vegetation. Summarizing, these results indicate that the FAO procedure to estimate table grape vineyard $K_{\mathrm{c}}$ using with the values from Allen and Pereira (2009) and adjusting for the effects of special crop management practices was sufficient to obtain reasonable estimates of $E T_{\mathrm{c}}$ under the conditions of this study.

\section{Conclusions}

The surface renewal method was used to determine values of $E T_{c}$ and crop coefficients of a table grape vineyard trained to a gable trellis system cropped under netting and a black plastic mulching. Values of daily $E T_{\mathrm{c}}$ were similar ( $<2 \%$ difference in average) regardless whether $\alpha$ was 0.6 or 1.0 for estimating sensible heat flux.

The seasonal patterns of $E T_{\mathrm{c}}$ and $E T_{\mathrm{o}}$ were similar across both years. Maximum daily $E T_{\mathrm{o}}$ was about $7.5 \mathrm{~mm} \mathrm{day}^{-1}$, while the highest monthly average $E T_{\mathrm{c}}$ ranged from 5.7 to $5.9 \mathrm{~mm}^{-1 a y}{ }^{-1}$. Seasonal $E T_{\mathrm{c}}$ was $843 \mathrm{~mm}$ in 2007 and $787 \mathrm{~mm}$ in 2008 for the period from May 1 though October.

The obtained experimental crop coefficient $\left(K_{\text {cexp }}\right)$ values included the effect of the netting and the black plastic mulching. These $K_{\text {cexp }}$ values were similar in both years, the maximum differences being observed in June and October mainly due to the different precipitation events. The experimental weekly crop coefficients $\left(K_{\text {cexp }}\right)$ varied between 0.64 and 1.2. Average $K_{\text {cexp }}$ was 0.79 and 0.98 during the mid-season and end-season stage, respectively. In previous studies, with similar ground cover fraction (above $70 \%$ ), mid-season $K_{\mathrm{c}}$ values were 
higher than those obtained in this work. The values of our $K_{\text {cexp }}$ here were lower compared with previously published $K_{\mathrm{c}}$ due to the effect of the netting and the plastic mulching which decreased the $E T_{\mathrm{c}}$. The $K_{\text {cexp }}$ value for end-season increased relative to the value during midseason. This behavior was similar to that reported by Netzer et al. (2009) and Williams and Ayars (2005b), and it could be due to a combination of factors, such as fall precipitation, increase in $K_{\mathrm{c}}$ due to small energy supply and wet surface when $E T_{\mathrm{o}}$ is small, and crop growth after veraison.

The relatively good agreement between the $K_{\text {cexp }}$ and the estimated $K_{\mathrm{cFAO}}$ values suggests that the Allen et al. (1998) provide reasonable estimates of the seasonal crop coefficients of an overhead table grape vineyard using the management practices outlined in this study, the netting over the canopy and the black plastic mulch.

Acknowledgments Work funded by the project Consolider CSD2006-00067 (Ministerio de Ciencia e Innovación, Spain). Thanks are due to the owner and manager of the commercial table grape orchard, to J. Negueroles, J. M. Faci, O. Blanco, M. Izquierdo, J. Gaudó, D. Mayoral, J. M. Acín, P. Paniagua, E. Medina, and C. Merino for technical and field assistance, and to the manuscript reviewers for their useful comments.

\section{Appendix}

Determination of the ramp parameters

The recorded high-frequency air temperature values were used to calculate the so-called structure functions (Snyder et al. 1996) each half-hour:

$S^{n}(r)=\frac{1}{m-j} \sum_{\mathrm{i}=1+\mathrm{j}}^{m}\left(T_{\mathrm{i}}-T_{\mathrm{i}-\mathrm{j}}\right)^{n}$

where: $m$ number of data points in the 30 -min interval measured at frequency ( $f=5 \mathrm{~Hz}$ in this case), $n$ power of the function, $j$ sample lag between data points corresponding to a time lag $(r=j / f) ; T_{\mathrm{i}}$ the ith temperature sample. For each thermocouple the powers 2,3 and 5 of the structure function were computed for sample lags of $1,2,3$ and 4 (i.e. for temperature readings $0.2,0.4,0.6$ and $0.8 \mathrm{~s}$ apart).

An estimate of the mean value for $A$ for each half-hour was determined by solving the following equation (Van Atta 1977; Paw U et al. 2005) for the real roots:

$A^{3}+p A+q=0$

where:

$p=10 S^{2}(r)-\frac{S^{5}(r)}{S^{3}(r)}$ and

$q=10 S^{3}(r)$

Finally, the inverse ramp frequency $\tau$ was estimated using the following equation:

$\tau=-\frac{A^{3} r}{S^{3}(r)}$

Using the Eqs. 5-9, $A$ and $\tau$ values were determined each half-hour for both thermocouples and for each time lag $(0.2,0.4,0.6$ and $0.8 \mathrm{~s})$.

\section{References}

Allen RG, Pereira LS (2009) Estimating crop coefficients from fraction of ground cover and height. Irrig Sci 28:17-34

Allen RG, Pruitt WO, Businger JA, Fritschen LJ, Jensen ME, Quinn FH (1996) Evaporation and transpiration. In: Heggern RJ, Wootton TP, Cecilio CB, Fowler LC, Hui SL (eds) Hydrology handbook, 2nd edn. American Society of Civil Engineers, New York, pp 125-252

Allen RG, Pereira LS, Raes D, Smith M (1998) Crop evapotranspiration: guidelines for computing crop water requirements, FAO irrigation and drainage paper no. 56. FAO, Rome

Anuario de Estadística Agroalimentaria (2008) In: Viñedo (Chapter 20.11.2). Madrid, Spain. http:/www.mapa.es/es/estadistica/pags/ anuario/2008/indice.asp. (Data retrieved on March 24 2010)

Castellví F, Martínez-Cob A (2005) Estimating sensible heat flux using surface renewal analysis and the flux-variance method. A case study over olive trees at Sástago (NE of Spain). Water Resour Res 41(9):W09422. doi: 10.1029/2005WR004035

Castellví F, Snyder RL (2009) Sensible heat flux estimates using surface renewal analysis. A study case over a peach orchard. Agric For Meteorol 149:1397-1402

Castellví F, Snyder RL (2010) A new procedure based on surface renewal analysis to estimate sensible heat flux: a case study over grapevines. J Hydrometeorol 11:496-508

Castellví F, Snyder RL, Baldocchi DD, Martínez-Cob A (2006) A comparison of new and existing equations for estimating sensible heat flux using surface renewal and similarity concepts. Water Resour Res 42:W08406. doi: 1029/2005WR004642

Castellví F, Snyder RL, Baldocchi DD (2008) Surface energy-balance closure over rangeland grass using the eddy covariance method and surface renewal analysis. Agric For Meteorol 148:11471160

Duce P, Spano D, Snyder RL, Paw U KT (1997) Surface Renewal estimates of evapotranspiration. Short canopies. Acta Hort 449:63-68

Duce P, Spano D, Snyder RL (1998) Effect of different finetermocouple design on high frequency temperature measurement. In: AMS proceedings of the 23rd conference on agriculture forest meteorology, Alburquerque, NM, 2-6 Nov, pp 146-147

Fereres E, Castel JR (1981) Drip irrigation management. In: Fereres E (ed) Drip irrigation management. Division of Agricultural Sciences, University of California, Leaflet no. 21259

Fereres E, Pruitt WO, Beutel JA, Henderson DW, Holzapfel E, Shulbach H, Uriu K (1981) ET and drip irrigation scheduling. In: Fereres E (ed) Drip irrigation management. University of California. Division of Agriculture Science No. 21259, p 8-13 
Ham JM (2005) Useful Equations and Tables in Micrometeorology. In: Viney MK, Hatfield JL, Baker JM (eds) Micrometeorology in agricultural systems. Agronomy Series No. 47. American Society of Agronomy, Crop Science of America, Soil Science Society of America, Madison, pp 533-560

Kirkham MB (2005) Principles of soil and plant water relations. Elsevier Academic Press, London, p 500

Martínez-Cob A, Faci JM (2010) Evapotranspiration of a hedgepruned olive orchard in a semiarid area of NE Spain. Agric Water Manage 97:410-418

Mengistu MG, Savage MJ (2010) Surface renewal method for estimating sensible flux. Water SA 36(1):9-18

Meyers TP, Baldocchi DD (2005) Current micrometeorological flux methodologies with applications in agriculture. In: Viney MK, Hatfield JL, Baker JM (eds) Micrometeorology in Agricultural Systems. Agronomy Monograph No. 47. American Society of Agronomy, Crop Science Society of America, Soil Science Society of America, Madison, pp 381-396

Möller M, Assouline S (2007) Effects of a shading screen on microclimate and crop water requirements. Irrig Sci 25:171-181

Monteith JL, Unsworth MH (2008) Principles of environmental physics, 3rd edn. Academic Press, Burlington $418 \mathrm{p}$

Netzer Y, Yao C, Shenker M, Bravdo BA, Schwartz A (2009) Water use and the development of seasonal crop coefficients for Superior Seedless grapevines trained to an open-gable trellis system. Irrig Sci 27:109-120

OIV (2006) International organisation of vine and wine. http://news. reseau-concept.net/images/oiv_uk/client/Commentaire_statistiques_ annexes_2006_EN.pdf. Data retrieved on 24 March 2010

Paw U KT, Qiu J, Su HB, Watanabe T, Brunet Y (1995) Surface renewal analysis: A new method to obtain scalar fluxes without velocity data. Agric For Meteorol 74:119-137

Paw U KT, Snyder RL, Spano D, Su HB (2005) Surface renewal estimates of scalar exchange. In: Hatfield JL, Baker JM, Viney MK (eds) Micrometeorology in Agricultural Systems. Agronomy Monograph No. 47. American Society of Agronomy, Crop Science Society of America, Soil Science Society of America, Madison, pp 455-483

Potter E, Wood J, Nicholl C (1996) SunScan canopy analysis system: user manual. Document SS1-UM-1.05. Delta-T Devices Ltd, Cambridge

Rana G, Katerji N, Introna M, Hammami A (2004) Microclimate and plant water relationship of the "overhead" table grape vineyard managed with three different covering techniques. Sci Hortic 102:105-120

Rodríguez JC, Grageda J, Watts CJ, Garatuza-Payan J, CastellanosVillegas A, Rodríguez-Casas J, Saiz-Hernández J, Olavarrieta V (2010) Water use by perennial crops in the lower Sonora watershed. J Arid Environ 74:603-610
Snyder RL, O'Connell NV (2007) Crop coefficients for microsprinker-irrigated clean-cultivated, mature citrus in an arid climate J Irrig Drainage Eng-ASCE 133:43-52

Snyder RL, Spano D, Paw U KT (1996) Surface renewal analysis for a sensible and latent heat flux density. Bound-Layer Meteor 77:249-266

Spano D, Duce P, Snyder RL, Paw U KT (1997a) Surface renewal estimates of evapotranspiration. Tall canopies. Acta Hort 449:63-68

Spano D, Snyder RL, Duce P, Paw U KT (1997b) Surface renewal analysis for sensible heat flux density using structure functions. Agric For Meteorol 86:259-271

Spano D, Snyder RL, Duce P, Paw U KT (2000a) Estimating sensible and latent heat flux density from grapevines canopies using surface renewal. Agric For Meteorol 104:171-183

Spano D, Duce P, Snyder RL, Paw U KT, Ferreira MI (2000b) Estimating tree and vine evapotranspiration with emphasis on surface renewal. Acta Hort 537:37-43

Spano D, Sicar C, Marras S, Duce P, Zara P, Arca A, Snyder RL (2008) Mass and energy flux measurements over grapevine using micrometeorological techniques. Acta Hort 792:623-630

Testi L, Villalobos FJ, Orgaz F, Fereres E (2006) Water requirements of olive orchards. I. Simulation of daily evapotranspiration for scenario analysis. Irrig Sci 24:69-76

Texeira AHC, Bastiaanssen WGM, Bassoi LH (2007) Crop water parameters of irrigated wine and table grapes to support water productivity analysis in the Sao Francisco river basin, Brazil. Agric Water Manage 97:31-42

Van Atta CW (1977) Effect of coherent structures on structure functions of temperature in the atmospheric boundary layer. Arch Mech 29:161-171

Vieira de Azevedo P, Monteiro JS, Rodrigues VP, Barbosa B, Nascimento T (2008) Evapotranspiration of "Superior" grapevines under intermitente irrigation. Agric Water Manage 49:211-224

Williams LE, Ayars JE (2005a) Grapevine water use and the crop coefficient are linear functions of shaded area measured beneath the canopy. Agric For Meteorol 132:201-211

Williams LE, Ayars JE (2005b) Water use of Thompson Seedless grapevines as affected by the application of gibberellic acid (GA3) and trunk girdling-practices to increase berry size. Agric For Meteorol 129:85-94

Williams LE, Phene CJ, Grimes DW, Trout TJ (2003) Water use of mature Thompson seedless grapevines in California. Irrig Sci 22:11-18

Willmott CJ (1982) Some comments on the evaluation of model performance. Bull Am Meteorol Soc 63:1309-1313 